\title{
Transportation safety in an urban condition
}

\author{
Alexey Shvetsov ${ }^{1}$, Alexander Balalaev ${ }^{2}$, Olga Grivanova ${ }^{3}$, Galia Kokieva ${ }^{4,}{ }^{,}$, and Larisa \\ Varlamova ${ }^{1}$ \\ ${ }^{1}$ North-Eastern Federal University, Belinsky str., 58, Yakutsk, 677000, Russia \\ ${ }^{2}$ Far East State Transport University, Serishev str., 47, Khabarovsk, 680000, Russia \\ ${ }^{3}$ Vladivostok State University of Economics and Service, Gogolya str., 41, Vladivostok, 127994, \\ Russia \\ ${ }^{4}$ Yakut State Agricultural Academy, Sergelyakhskoye sh., 3, Yakutsk, 677007, Russia
}

\begin{abstract}
This study is explores the problem of cars entry in to subway stations. Cars been driven in to subway stations in many countries including France, Russia, Belarus, Belgium, Italy, etc. Sometimes this results in fatalities or injuries and stoppage of work at the station. In this article, we have systematized statistics on cases of cars entry in to subway stations around the world and suggest a resolution for this problem. The proposed in the study of an anti-ram protective bollard capable of blocking cars driving into stations could serve as such a resolution. Then we develop an method that of determined the optimal location of anti-ram protective bollards. The authors tested the developed methodology on the example of the Prospect Mira station (Kaluzhsko-Rizhskaya line) of the Moscow subway. Equipping territories around subway stations with the developed an bollards will resolve the problem of protecting subway stations against cars entering their territories and will protect people.
\end{abstract}

\section{Introduction}

The authors explored the problem of cars entry in to the entrances of subway stations. Investigation showed that such accidents have taken place in different countries of the world including France, Russia, Belarus, Belgium, Italy, etc.

The bus that drove into the entrance of subway station "Slavyansky Boulevard" in Moscow (Russian Federation, 2017) (Fig. 1, 2) caused five death, cars that drove into subway stations "Profsoyuznaya" in Moscow (Russian Federation, 2016) and Chaussee d'Antin La Fayette in Paris (France, 2007) caused the stoppage of work subway stations. The cars that drove into the subway stations "Auch" in Paris (France, 2004) and "Leo Tolstoy Square" in Kiev (Ukraine, 2004) caused wounded people.

\footnotetext{
*Corresponding author: transport-safety@mail.ru
} 


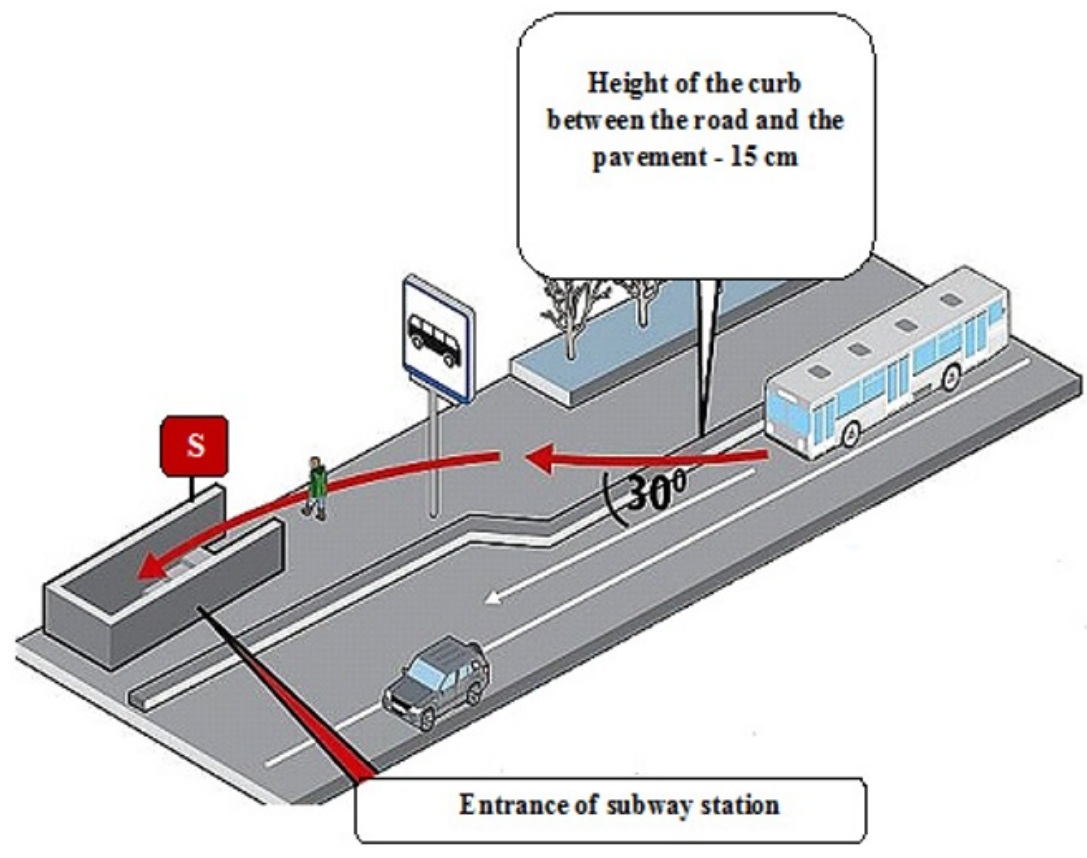

Fig. 1. Scheme entry bus in to the entrance of subway station "Slavyansky Boulevard" (Moscow, 2017), Source: https://gala-gala15.livejournal.com/478288.html

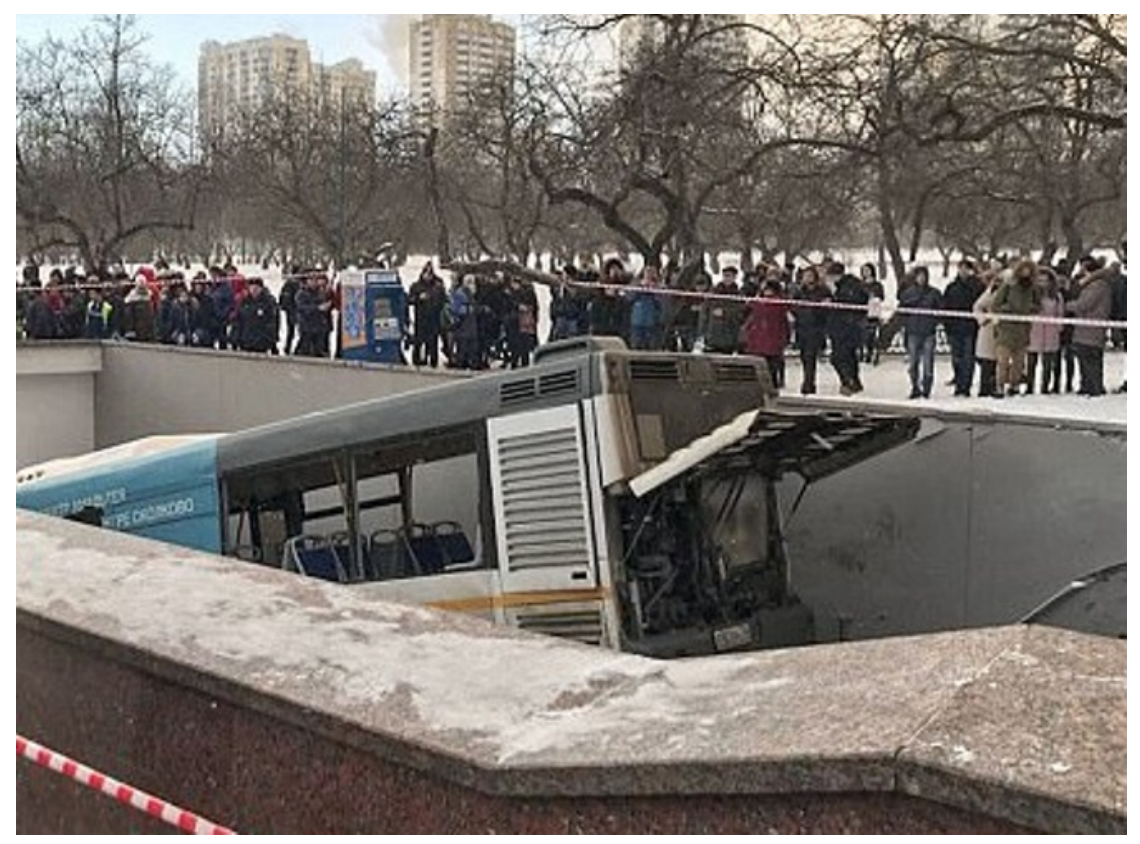

Fig. 2. The bus that drove into the entrance of subway station "Slavyansky Boulevard" in Moscow (Russian Federation, 2017), Source: https://www.dailymail.co.uk/news/article-5211397/At-fourpeople-killed-bus-Moscow.html 
Statistics on the incidents of cars entry in the subway stations have been systematized in Table 1.

Table 1. Incidents of cars entry in the subway stations.

\begin{tabular}{|c|c|c|c|}
\hline Year & $\begin{array}{c}\text { Subway } \\
\text { system }\end{array}$ & Subway station & Car \\
\hline 2003 & Paris & "Balard" & Passenger car \\
\hline 2004 & Kiev & "Leo Tolstoy Square" & Passenger car \\
\hline 2004 & Paris & "Auch" & Passenger car \\
\hline 2011 & Minsk & "Mogilevskaya" & Truck \\
\hline 2012 & Paris & $\begin{array}{c}\text { "Chaussee d'Antin La } \\
\text { Fayette" }\end{array}$ & Off-road car \\
\hline 2012 & Baku & "Gyandzhlik" & Off-road car \\
\hline 2013 & Moscow & "Voikivskaya" & Motorbike \\
\hline 2016 & Rome & "Magliana" & Passenger car \\
\hline 2016 & Brussels & "Clemanso" & Passenger car \\
\hline 2016 & Moscow & "Profsoyuznaya" & "Slavyansky \\
\hline 2017 & Moscow & Boulevard" & Passenger \\
\hline
\end{tabular}

The statistics (Table 1) show that the problem of protecting subway stations against penetration by cars does exist. A cars that drives into a subway station can traumatize or kill people who are at that moment inside the station or can cause a fire at the station in consequence of the explosion of fuel in the car's tank.

The studies show that free access to subway stations poses a threat to terrorist attacks with use of cars [1-16].

\section{Prevent of cars entry in the subway stations}

The problem of protecting subway stations can be resolved by an anti-ram protective bollard (ARPB) which will ensure efficient protection against driving into subway stations of the following cars:

1. passenger cars including jeeps

2. off-road cars;

3. bus;

4. trucks;

5. motorbikes.

This device should be located in areas of possible entrance and blocks cars from penetration into the territory around the station by retractable obstructive posts. A general view of the anti-ram protective device is shown in Figure 3. 


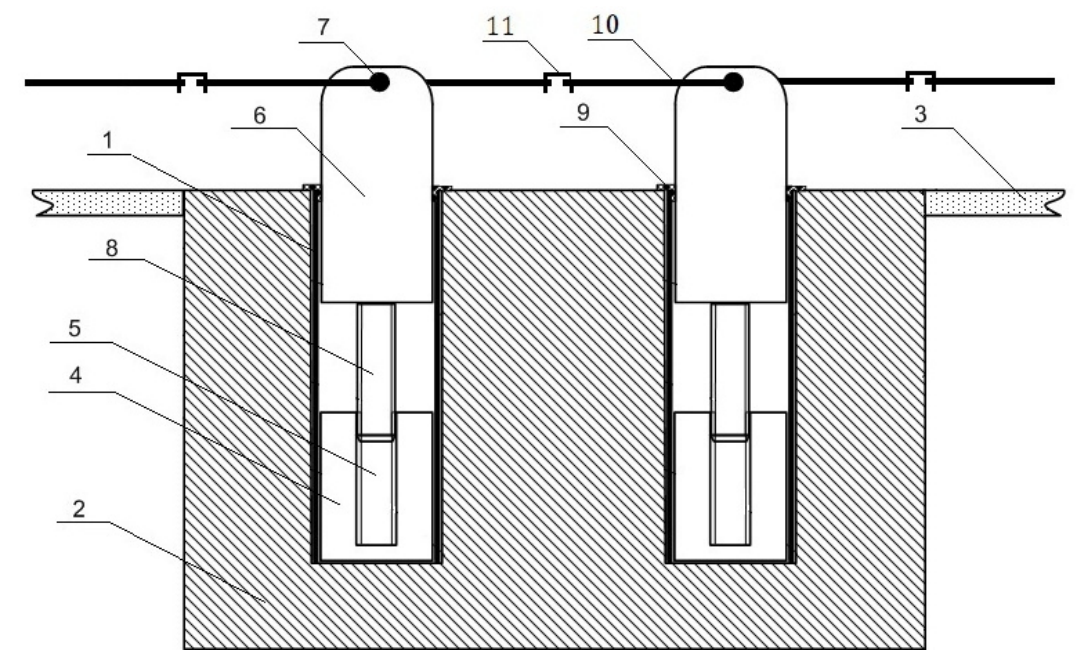

Fig. 3. Two ARPB installed in a joint foundation.

ARPB consists of the following elements: the casing 1, mounted on a concrete foundation 2 (the concrete foundation is leveled with the asphaltic-concrete pavement 3); a blocking element consisting of a cylindrical foundation 4 , with a screw hole 5 in its central and barrage post 6 with a mounting hole 7 in its upper part and a screw element 8 in its lower part; a rubber tightening ring 9; an additional blocking element 10; and a connection element 11 .

ARPB is of increased resistance against ramming due to the bi-layer casing of the barrage post: the external layer is made of high-strength steel.

ARPB has the function of raising and lowering the barrage post (Figure 4).

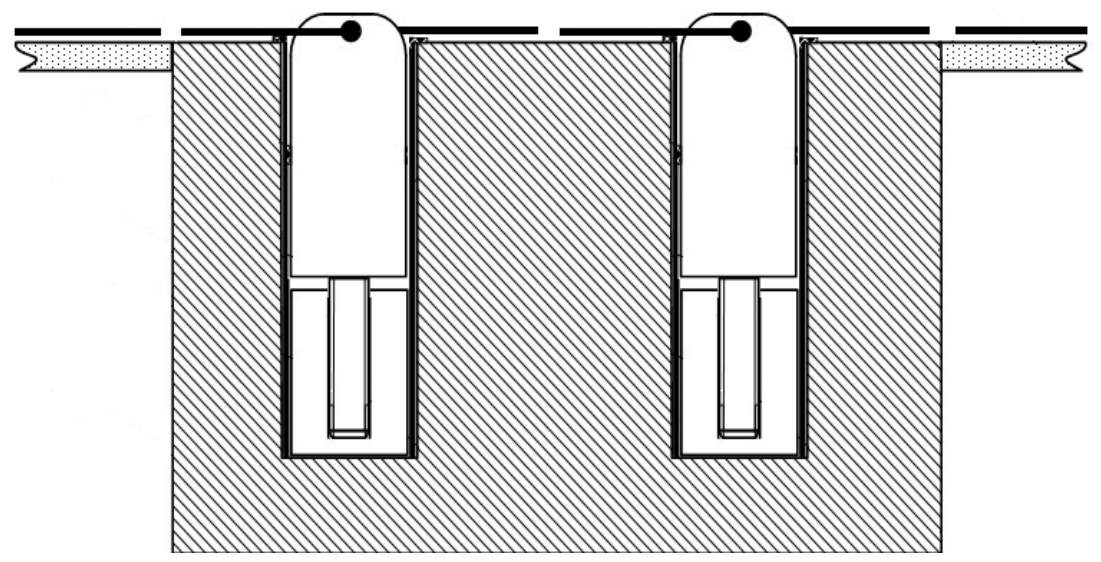

Fig. 4. ARPBs with lowered protective bollards.

ARPB specifics:

-ARPB has the function of lowering and raising of the protective bollard;

-ARPB has a mechanical activator for moving the bollard which is independent of any External Systems. The bollard is lowered by twisting into the steel base. The twistinginsertion is performed through the physical effort of a human being revolving it clockwise with the additional protective element (10 in Fig. 3) which serves as a lever. The bollard has a screw element in its lower part; this element fits into the hole in the case of the 
foundation. This hole has a thread for twisting the screw element in to lower the bollard; when rotated in reverse (unscrewed), the bollard raises;

- the structure of ARPB is maximally simplified and allows anyone without special training to lower bollards in 1-1.5 min. which ensures Emergency Services cars thoroughfare when they arrive;

-ARPB the diameter of the bollard is $375 \mathrm{~mm}$;

-ARPB has the special shape of a bollard rounded in its upper part and has no sharp corners or projecting parts.

ARPB meets all the specific features of subway systems and therefore it can be applied to protect subway stations against cars driving into the entrances of stations.

\section{Method of Location Anti-ram Protective Bollards at Subway Stations}

The use of a methodology for choosing the location of ARPBs at subway stations is a prerequisite for ensuring effective protection of subway stations. This condition can be justified by the fact that almost all subway stations are built according to individual projects and, as a rule, are located in conditions of dense urban development. On the pedestrian paths adjacent to the stations, a large number of pedestrians moves. On adjacent roads there is a dense stream of transport. The situation becomes especially serious at peak times. Placing ARPBs in such conditions without scientifically grounded guidelines creates risks that the protection of stations will not be sufficiently effective. The optimal location of the ARPB should be determined specifically for each station based on the use of the method of placement of ARPBs developed by the author and described below.

Placement of anti-ram barriers on the territory adjacent to the subway station can be divided into two stages:

Stage 1 - the choice of location;

Stage 2 - determination of the density of placement of ARPBs.

\subsection{Stage 1 - Choosing a location}

One of the conceptual issues affecting the performance of ARPB when blocking the intrusion of an intruder using a motor car is the correct choice of the location of ARPBs on the territory adjacent to the subway station.

The reasons for the need to correctly calculate the location of ARPB:

- efficiency of application - the correct placement will ensure guaranteed blocking of the passage of cars;

- the cost of equipping the facility ARPB - proper placement will avoid the additional costs associated with the installation of unnecessary protective devices.

The territory near the subway station, on which the passage of cars must be blocked, is a pedestrian zone adjacent to the entrance to the subway station, since it is the entrance to the station and the congestion of people entering / leaving the station.

The boundaries of the pedestrian zone adjacent to the entrance to the subway station must be determined individually for each station - they are defined as the boundaries of the territory at the entrance to the subway station, where people gather in / out of the subway station during rush hours.

For example, according to statistics, rush hours in the Moscow subway are: 8.00-9.00 in the morning and 18.00-19.00 in the evening, while the maximum traffic is observed on days of the week on Thursday and Friday [17]. 
If it is technically possible for cars to enter a pedestrian zone not only from the side of the roadway, but, for example, along a sidewalk or other non-carriageway territory, the boundary of these territories and the pedestrian zone adjacent to the station entrance is also equipped with ARPB.

\subsection{Stage 2 - determination of the density of placement of ARPB}

To prevent small cars from driving between ARPB installed near subway stations, we need to correctly calculate the spacing between ARPB. Firstly, we need to calculate the maximum distance apart for the arrangement of ARPB.

To calculate the maximum permissible distance between ARPBs that will ensure guaranteed blocking of the passage of small cars we need to know the minimum dimension parameters of existing cars. For this purpose we have analyzed standard cars with minimum dimension parameters (Table 2).

Table 2. Cars parameters.

\begin{tabular}{|c|c|c|c|}
\hline Cars & Length, $\mathrm{mm}$ & Width, $\mathrm{mm}$ & Height, $\mathrm{mm}$ \\
\hline $\begin{array}{c}\text { Mercedes SMART } \\
\text { ForTwo }\end{array}$ & 2700 & 1560 & 1540 \\
\hline Suzuki Twin & 2735 & 1475 & 1450 \\
\hline Fiat Seicento & 3319 & 1508 & 1440 \\
\hline Citroen C1 & 3430 & 1630 & 1460 \\
\hline Toyota iQ & 2985 & 1680 & 1500 \\
\hline Aston Martin Cygnet & 3078 & 1680 & 1500 \\
\hline $\begin{array}{c}\text { Autobianchi } \\
\text { Transformabile }\end{array}$ & 2985 & 1340 & 1320 \\
\hline
\end{tabular}

Following the analysis we have obtained data on the minimal width of a car which is $1340 \mathrm{~mm}$. In order to resolve the problem of guaranteed blocking of cars we must introduce the reliability index (constricting the maximum distance between ARPB), which is adopted as $10 \%$ of the established minimal width of a car. This is determined by a theoretical probability of driving cars into a station that either have not been considered during our research or are non-standard, i.e. those with less width.

The maximum distance between the ARPBs Rmax is calculated according to the formula

$$
R_{\max }=X_{v h}-\left(X_{v h} \cdot X_{b r}\right)-X_{p p}
$$

where $X v h$ is the width of the car, mm;

$X b r$ is the car blocking reliability index;

$X p p$ is the diameter of the protective post, $\mathrm{mm}$.

I.e., if $X v h=1340 \mathrm{~mm}$ (data from Table 2), $X b r$ is $10 \%$ of $X v h, X p p=375 \mathrm{~mm}$, so Rmax $=831.0 \mathrm{~mm}$.

The density of spacing anti-ram bollards $R p l$ is determined by the formula

$$
R_{p l}=R_{\max }+X_{p p}
$$

Thus, if Rmax $=831.0 \mathrm{~mm}, X p p=375 \mathrm{~mm}$, the spacing density of ARPBs calculated according to formula (2) is one device per $1206.0 \mathrm{~mm}$.

The author tested the developed methodology on the example of the Prospect Mira station (Kaluzhsko-Rizhskaya line) of the Moscow subway.

The boundaries of the pedestrian zone adjacent to the entrance to the subway station and the possible entry points of cars to the pedestrian zone, including along the pedestrian paths, were determined. Taking into account the factors affecting the choice of location of anti- 
ram barriers, the ARPB placement line was determined, which allows you to completely block unauthorized entry of cars to the pedestrian zone adjacent to the station entrance and at the same time spend the minimum amount of ARPB.

The resulting layout of ARPB is shown in Figure 5.

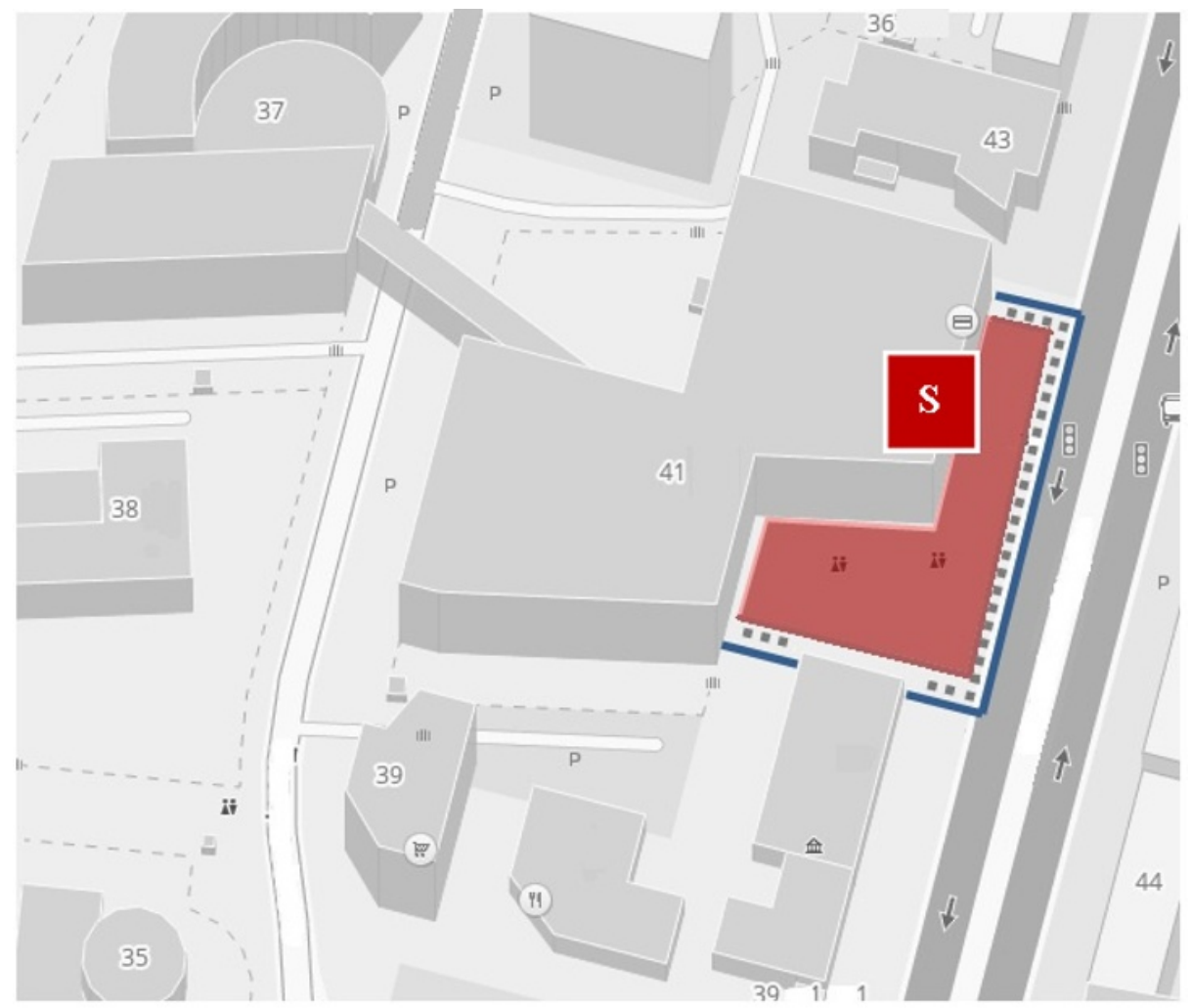

Key:

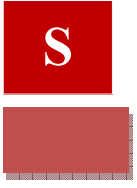

- Entrance of subway station "Prospect Mira";

- Pedestrian zone adjacent to the station entrance;

- Line placement ARPB;

- Possible places of entry of cars to the pedestrian zone adjacent to the entrance to the station.

Fig. 5. Location of ARPBs on the territory near the station "Prospect Mira" ("Kaluzhsko-Rizhskaya" line of the Moscow Subway) Source: (C) of Map: 2GIS

\section{Conclusions}

The research we conducted ascertained the existence of the problem of protecting against of cars entry in to the entrances of subway stations. This can become the reason for stoppage of work and, what is much worse, can kill people who are present at that moment in the station. The drove of a bus into the entrance of subway station "Slavyansky Boulevard" in 
Moscow (Russian Federation, 2017) which caused five death and interrupted the work of the station can serve as an illustration.

We proposed a anti-ram protective bollard and developed a method for placing it at subway stations. Equipping subway stations with such devices will resolve the problem of protecting against of cars entry in to the entrances of subway stations.

\section{References}

1. R. Borum, R. Fein, B. Vossekuil, A dimensional approach to analyzing lone offender terrorism. Aggress Violent Behav 17(5), 389-396 (2012)

2. V. Ceccato, A. Newton, Practical Challenges and New Research Frontiers for Safety and Security in Transit Environments. In: Vania Ceccato and Andrew D. Newton (eds.). Safety and Security in Transit Environments: An Interdisciplinary Approach, 362-384. Palgrave Macmillan (2015) DOI 10.1057/9781137457653_20

3. F. De Cillis, M. De Maggio, C. Pragliola, R. Setola, Analysis of criminal and terrorist related episodes in railway infrastructure scenarios. J. of Hom. Sec. and Em. Man. 10(2), 447-476 (2013)

4. F.L. Edwards, D.C. Goodrich, J. Griffith, Emergency management training for transportation agencies. Mineta Transp. Inst. Rep. 12(70), 137-156. Mineta transp. Inst., San Jose (2016)

5. L. Faramondi, R. Setola, Identification of Vulnerabilities in Networked Systems: Theories, Methods, Tools and Technologies. Crit. Inf. Sec. and Resil., 3-283 (2019) DOI https://doi.org/10.1007/978-3-030-00024-0

6. B. Hasisi, S. Perry, Y. Ilan, Y. et al., Concentrated and close to home: the spatial clustering and distance decay of lone terrorist vehicular attacks. J Quant Criminol 11(4), 124-135 (2019) https ://doi.org/10.1007/s1094 0-019-09414 -Z

7. Y. Heng, Y. Wang, F. Wang, P. Qiu, Understanding impacts of security check on passenger flow in a metro station and improving measures: a case study in Guangzhou. J. Adv. Transp. 19(1), 85-97, China (2019) https://doi.org/10.1155/2019/74385 45

8. B.A. Lyovin, A.V. Shvetsov, R. Setola, S.V. Shvetsova, M. Tessei, Method for Remote Rapid Response to Transportation Security Threats on High Speed Rail Systems. Intern. J. of Crit. Inf. 15(4), 324-335 (2019) DOI: 10.1504/IJCIS.2019.10023736

9. G. LaFree, L. Dugan, M. Xie, P .Singh, Spatial and temporal patterns of terrorist attacks by ETA 1970 to 2007. J. Quant Criminol 28(1), 7-29 (2012)

10. E. Matsika, C. O’Neill, U. Battista, M. Khosravi, A. Laporte, E. Munoz, Development of risk assessment specifications for analysing terrorist attacks vulnerability on subway and light rail systems. Transp. Res. Proc. 14, 1345-1354 (2016)

11. S. Meyer, Reducing harm from explosive attacks against railways. Sec. J. 25(4), 24-37 (2012) DOI 10.1057/sj.2011.23

12. Z. Marchment, N. Bouhana, P. Gill, Lone actor terrorists: a residence-to-crime approach. Terror. Polit. Viol. 25(3), 75-95 (2018) https://doi.org/10.1080/09546553.2018.1481050Google Scholar

13. R. Setola, S. De Porcellinis, M. Sforna, Critical infrastructure dependency assessment using the input-output inoperability model. Intern. J. of Crit. Inf. Prot. 2, 170-178 (2009) 
14. R. Setola, A. Sforza, V. Vittorini, C. Pragliola, Railw. Inf. sec. Topics in safety, risk, reliability and quality. TSRQ. 27, 362-384. Springer, Cham (2015)

15. S. Starita, M.P. Scaparra, Passenger railway network protection: a model with variable post-disruption demand service. J. Oper. Res. Soc. 17(6), 224-237 (2017) doi.org/10.1057/s41274-017-0255-y

16. B. Schuurman, L. Lindekilde, S. Malthaner, F. O'Connor, P. Gill, N. Bouhana, End of the lone wolf: the typology that should not have been. Stud Conflict Terrorism 7(2), 133-151 (2018) https://doi.org/10.1080/1057610X.2017.1419554

17. Metrobits World metro database (Online) (2017) http://mic-ro.com/metro /table .html 